\title{
Features of the $F 3$ layer occurrence over the equatorial location of Trivandrum
}

\author{
V. Sreeja, S. Ravindran, and T. K. Pant \\ Space Physics Laboratory, Vikram Sarabhai Space Centre, Trivandrum, India \\ Received: 15 March 2010 - Revised: 7 September 2010 - Accepted: 14 September 2010 - Published: 24 September 2010
}

\begin{abstract}
The general features of the F3 layer occurrence over the magnetic equatorial location of Trivandrum $\left(8.5^{\circ} \mathrm{N} ; 77^{\circ} \mathrm{E}\right.$; dip lat $\left.\sim 0.5^{\circ} \mathrm{N}\right)$ in India during the period from 1996-2005 are presented using the ionosonde observations. The study brings out that the F3 layer occurrence over Trivandrum is weak and rare compared to the other equatorial locations. The F3 layer occurrence is relatively more pronounced during the magnetically active conditions, thus indicating the dependence of the layer formation over Trivandrum on magnetic activity. It is also observed that the percentage occurrence of the F3 layer decreases with increasing solar activity.
\end{abstract}

Keywords. Ionosphere (Equatorial ionosphere) - Magnetospheric physics (Electric fields)

\section{Introduction}

The combination of the electrodynamic drift, thermospheric winds and diffusion on the plasma over the magnetic equator leads to a number of peculiar features over the equatorial and low latitude ionosphere. The appearance of an additional ionization layer above the F2 peak is an example of the aforesaid equatorial features. The additional stratification of the F2 layer over low and mid latitudes was known as early as the 1940s (Sen, 1949; Ratcliffe, 1951; Skinner et al., 1954; Heisler, 1962), though the stratification could not be explained. These investigators attributed the traveling disturbances and dynamics involving vertical ionic drifts as the possible sources of these stratifications. Modeling studies of the Equatorial Ionisation Anomaly and its effects using the Sheffield-University-PlasmasphereIonosphere-Model (SUPIM) (Bailey and Balan, 1996) re-

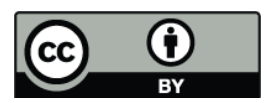

Correspondence to: V. Sreeja

(v.sreeja@gmail.com) vealed the possibility of an additional layer above the F2 peak, which was called the G layer (Balan and Baliey, 1995). Later, it was renamed as the F3 layer, since it was not found to involve any new ionization source or neutral species. The first modeling of the F3 layer (Balan and Baliey, 1995) was for the Jicamarca longitude $\left(12^{\circ} \mathrm{S}, 77^{\circ} \mathrm{W}\right.$, dip $\left.2^{\circ} \mathrm{N}\right)$, and later it was extended to the Brazilian and Indian longitudes (Balan et al., 1997).

Following the first detection of the F3 layer at Fortaleza $\left(3^{\circ} \mathrm{S}, 38^{\circ} \mathrm{W}\right.$, dip $2^{\circ} \mathrm{S}$ ) in Brazil (Balan et al., 1997; Jenkins et al., 1997), a possible physical mechanism for the layer formation, its statistics of occurrence and the day-to-day variability were reported (Balan et al., 1998, 2000; Batista et al., 2002). According to the physical mechanism of the F3 layer formation, as suggested by Balan et al. (1998), the layer usually forms during daytime ( 08:30-16:30 LT) within $\pm 10^{\circ}$ magnetic latitude, from the production of ionization and unique electrodynamics of the equatorial F-region. The F3 layer is expected to form centered at that equatorial location where the combined effects of the upward $\boldsymbol{E} \times \boldsymbol{B}$ drift and equatorward neutral wind provide a vertically upward plasma drift velocity. This velocity causes the F2 peak to drift upward and form the F3 layer, while a normal F2 layer develops at lower altitudes through the usual photochemical and dynamical effects of the equatorial region. Once an F3 layer is formed, its peak density $(\mathrm{NmF} 3)$ remains greater than that of the F2 layer $(N m \mathrm{~F} 2)$ for a period of time, when both the layers can be detected by the ground-based ionosondes. At later times, when $N m \mathrm{~F} 3$ becomes less than $N m \mathrm{~F} 2$, the F3 layer disappears from the ionograms, and then the layer can be observed by topside sounders as topside ledges. After sunset, due to the absence of photoionization, the F3 layer formation ceases, though topside ledge continue to exist well after sunset.

Sayers et al. (1963) were the first to detect the topside ledges in the equatorial ionosphere using a Langmuir probe onboard the Ariel-I satellite and they predicted that the 
Table 1. Variation in the critical frequencies of the $\mathrm{F} 2(f o \mathrm{~F} 2)$ and $\mathrm{F} 3(f o \mathrm{~F} 3)$ layer for the days shown in Fig. 1a.

\begin{tabular}{|c|c|c|c|c|c|c|}
\hline \multirow{2}{*}{$\begin{array}{c}\text { Date } \rightarrow \\
\text { Time (IST) } \downarrow\end{array}$} & \multicolumn{2}{|c|}{12 August 2000} & \multicolumn{2}{|c|}{3 October 2003} & \multicolumn{2}{|c|}{30 March 2005} \\
\hline & $\begin{array}{r}f o \mathrm{~F} 2 \\
(\mathrm{MHz})\end{array}$ & $\begin{array}{r}f o \mathrm{~F} 3 \\
(\mathrm{MHz})\end{array}$ & $\begin{array}{r}f o \mathrm{~F} 2 \\
(\mathrm{MHz})\end{array}$ & $\begin{array}{r}f_{o} \mathrm{~F} 3 \\
(\mathrm{MHz})\end{array}$ & $\begin{array}{r}f o \mathrm{~F} 2 \\
(\mathrm{MHz})\end{array}$ & $\begin{array}{r}f o \mathrm{~F} 3 \\
(\mathrm{MHz})\end{array}$ \\
\hline 09:00 & 12.5 & & 11.6 & & 8.7 & \\
\hline $09: 15$ & 12.3 & & 11.6 & & 7.9 & 8.6 \\
\hline 09:30 & 12.7 & & 11.7 & & 8.0 & 8.5 \\
\hline $09: 45$ & 12.7 & & 11.6 & & & \\
\hline $10: 00$ & 13.2 & & 9.4 & 11.6 & & \\
\hline $10: 15$ & 13.1 & & 9.6 & 11.5 & & \\
\hline $10: 30$ & 13.2 & & 9.9 & 11.5 & & \\
\hline $11: 30$ & 13.6 & & & & & \\
\hline $11: 45$ & 7.7 & 13.5 & & & & \\
\hline $12: 00$ & 9.1 & 13.4 & & & & \\
\hline $12: 30$ & 9.8 & 12.8 & & & & \\
\hline
\end{tabular}

topside ionograms would reveal the ledges as cusps. Lockwood and Nelms (1964) and King et al. (1964) detected the ledges as cusps in the topside ionograms recorded by the topside sounder onboard the Alouette-I satellite. Raghavarao and Sivaraman (1974) were the first to detect the topside ledges in the Indian longitudes using the ISIS-II topside sounder. Thampi et al. (2005) were the first to show that the F3 layer and the topside ledges could be observed in the latitudinal profiles of Total Electron Content (TEC) measured by the low earth orbiting satellites. Using the Ohzora (EXOSC) and ISIS-II satellite, Uemoto et al. $(2004,2006)$ presented a statistical analysis of the topside ledges in the equatorial ionosphere and concluded that except for the seasonal difference in the occurrence probability, the characteristics of the F3 layer and the topside ledges are similar.

Based on the average upward drift (Fejer et al., 1991) and the Horizontal Wind Model (HWM) (Hedin et al., 1991), a distinct F3 layer was predicted to occur on the summer side of the geomagnetic equator (Balan et al., 1998). However, observations show that the layer occurs even during the winter months (Batista et al., 2002; Rama Rao et al., 2005), which was explained as due to the variability in the driving forces like the drift, wind, tides and waves (Balan et al., 1998). There had been several observations of the F3 layer from various equatorial locations. Lynn et al. (2000) presented the latitudinal dependence of the F3 layer occurrence at the equatorial latitudes in South East Asia using the observations from both oblique and vertical ionosondes. They showed that the F2 layer stratification occurred over a narrow region between the magnetic equator and the peak of the southern equatorial anomaly, a result which corroborates with Jenkins et al. (1997). The first simultaneous observation of the F3 layer on either side of the geomagnetic equator was reported by Uemoto et al. (2007). Rama Rao et al. (2005) reported the ionosonde observations of the F3 layer over Waltair $\left(17.7^{\circ} \mathrm{N} ; 83.3^{\circ} \mathrm{E}\right.$; dip lat $\left.\sim 8.2^{\circ} \mathrm{N}\right)$ in India. Zain et al. (2008) reported the observations of the F3 layer at the equatorial regions in Malaysia during 2005. The solar activity dependence of the F3 layer occurrence was studied by Batista et al. (2002) at Fortaleza and by Rama Rao et al. (2005) at Waltair, which confirmed that the layer becomes less distinct and less frequent as the solar activity increases.

Most of the earlier studies of the F3 layer have been made during the magnetically quiet days. However, recently, the occurrence of the F3 layer during magnetically disturbed periods has received attention (Balan et al., 2008; Paznukhov et al., 2007; Sreeja et al., 2009). There had been observations of continuous geomagnetically active days when the layer was observed on certain days and not observed on other days (Balan et al., 2000; Rama Rao et al., 2005). These studies point to the fact that the occurrence of the F3 layer does not depend on the magnetic activity.

This paper reports the general features of the F3 layer occurrence over the magnetic equatorial location of Trivandrum $\left(8.5^{\circ} \mathrm{N} ; 77^{\circ} \mathrm{E}\right.$; dip lat $\left.\sim 0.5^{\circ} \mathrm{N}\right)$ in India under varying magnetic activity levels over a solar cycle, with emphasis on a solar maximum year of 2001 and a minimum year of 2005 .

\section{Data}

For the present study, we have made use of the quarter hourly ionograms recorded using the digital ionosonde model IPS42 at Trivandrum for the period of 1996-2005 to obtain the characteristics of the F3 layer over the magnetic equator. The number of available ionograms per day is 96 with the routine 15 min sounding. Also, during the time interval (08:0016:00 IST), when the probability of F3 layer occurrence is large, 33 ionograms were available.

\section{Observations}

\subsection{General features of the F3 layer}

The time sequences in the development of the F3 layer over Trivandrum on 3 days under three different seasons and solar activity conditions are shown in the different panels of Fig. 1a (left panel). The ionograms at the corresponding time during three days when F3 is absent is shown in the right panel of Fig. 1a for comparison. It can be observed from Fig. 1a that virtual height of the F3 layer $\left(h^{\prime} \mathrm{F} 3\right)$ when it first appears, is typically between 400 and $500 \mathrm{~km}$ and then with the passage of time, the layer is observed to gradually drift upwards. The time variation in critical frequency of the F2 $(f o \mathrm{~F} 2)$ and $\mathrm{F} 3(f o \mathrm{~F} 3)$ layer during the days shown in Fig. 1a is illustrated in Table 1. From Table 1, it is clear that on 12 August 2000, foF2 is around $13.6 \mathrm{MHz}$ at $11: 30 \mathrm{IST}$. At 11:45 IST, it decreases to $7.7 \mathrm{MHz}$, while $f o \mathrm{~F} 3$ is $13.5 \mathrm{MHz}$, the difference between $f o \mathrm{~F} 2$ and $f o \mathrm{~F} 3$ is $\sim 6 \mathrm{MHz}$. On 3 October 2003, $f o \mathrm{~F} 2$ before the development of the $\mathrm{F} 3$ layer (i.e. around 09:45 IST) is $11.6 \mathrm{MHz}$. By around 10:00 IST, 

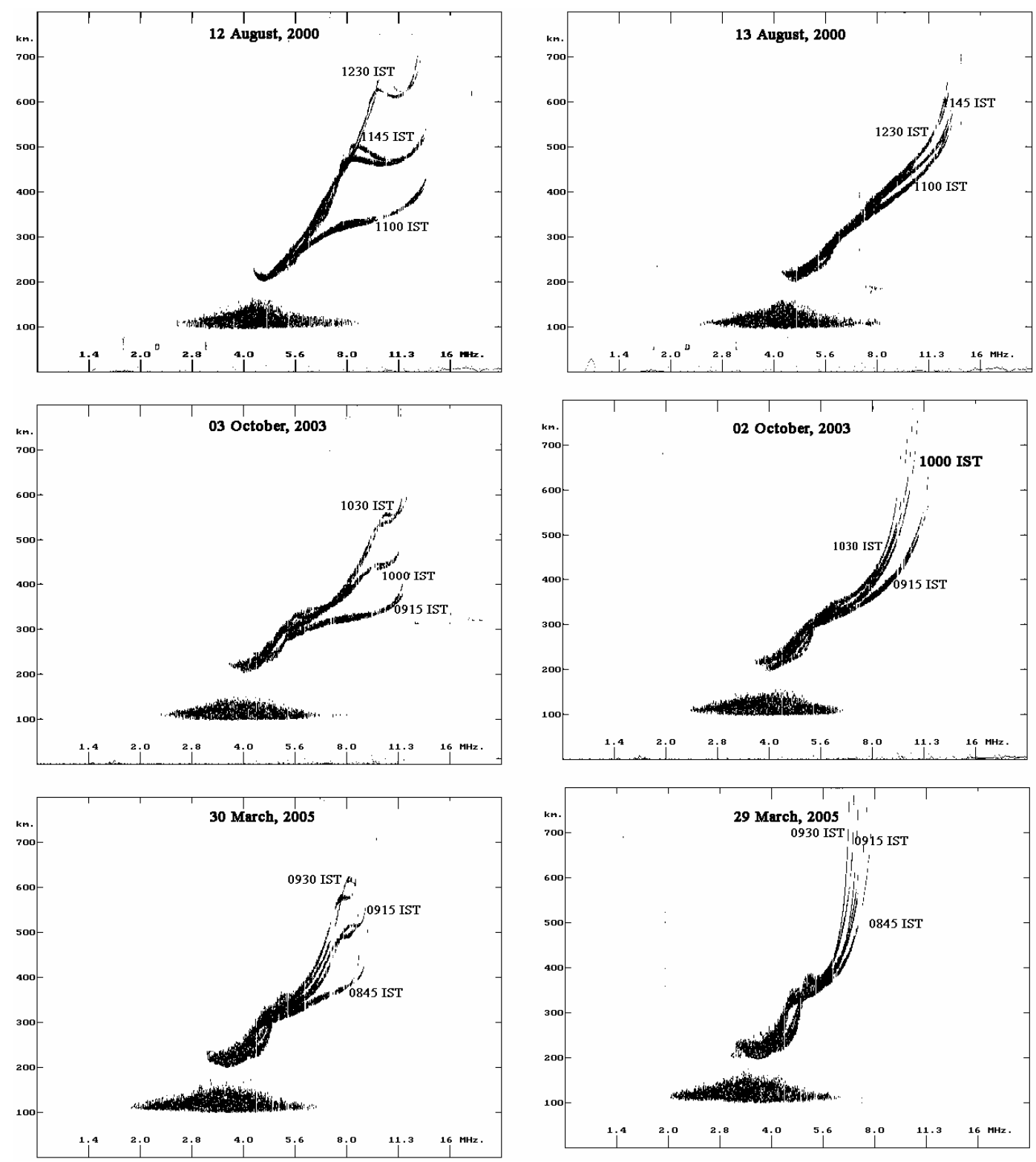

Fig. 1a. Left panel: sample ionograms illustrating the temporal evolution of F3 layer at Trivandrum on different days. Right panel: sample ionograms at the corresponding times when F3 layer is absent.

this decreases to $9.4 \mathrm{MHz}$, while $f \circ \mathrm{F} 3$ is $11.6 \mathrm{MHz}$. In this case, the difference between $f o \mathrm{~F} 2$ and $f o \mathrm{~F} 3$ is $\sim 2 \mathrm{MHz}$. At 09:00 IST on 30 March 2005, before the development of the F3 layer, $f_{o} \mathrm{~F} 2$ is $8.7 \mathrm{MHz}$. With the development of the F3 layer at $09: 15 \mathrm{IST}, f_{o} \mathrm{~F} 2$ decreases to $7.9 \mathrm{MHz}$ and $f o \mathrm{~F} 3$ is $8.6 \mathrm{MHz}$, the difference between $f o \mathrm{~F} 2$ and $f o \mathrm{~F} 3$ is $\sim 1 \mathrm{MHz}$. Figure $1 \mathrm{~b}$ illustrates the mean critical frequencies of the F2 (averaged between 08:00-16:00 IST-shaded histogram) and F3 layer (open histogram) and their difference for the days shown in Fig. 1a. It can be observed from this figure that the mean $f o \mathrm{~F} 3$ exceeds the mean $f o \mathrm{~F} 2$ by $\approx 2 \mathrm{MHz}$ on 12 August 2000 , by $\approx 1 \mathrm{MHz}$ on 3 October 2003 and by $\approx 0.5 \mathrm{MHz}$ on 30 March 2005.
Hence, it is observed that for all the cases presented here, the appearance of the F3 layer is associated with a decrease in $f o \mathrm{~F} 2$. Further, the $f o \mathrm{~F} 2$ just before the appearance of the F3 layer almost matches with the $f_{o} \mathrm{~F} 3$, when the F3 layer appears, indicating that the F3 layer is not formed by the additional production of ionization, but as a result of the redistribution of ionization. The decrease in $f o \mathrm{~F} 2$ with the appearance of F3 is expected and it corroborates with the earlier results (Balan et al., 1997; Rama Rao et al., 2005; Zain et al., 2008). 


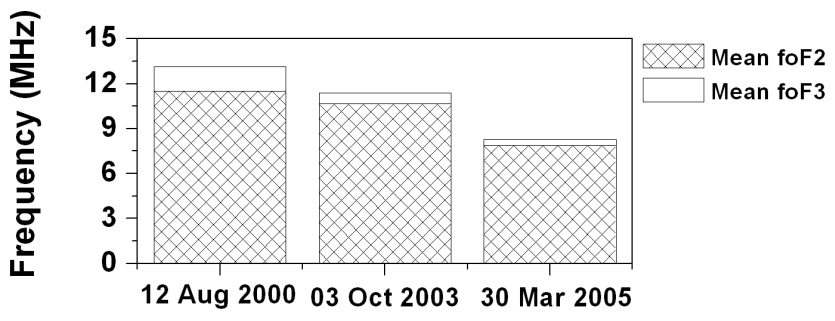

Fig. 1b. Histogram illustrating the mean critical frequencies of F2 (averaged between 08:00-16:00 IST-shaded) and F3 (open) layers at Trivandrum for the days shown in Fig. 1a.

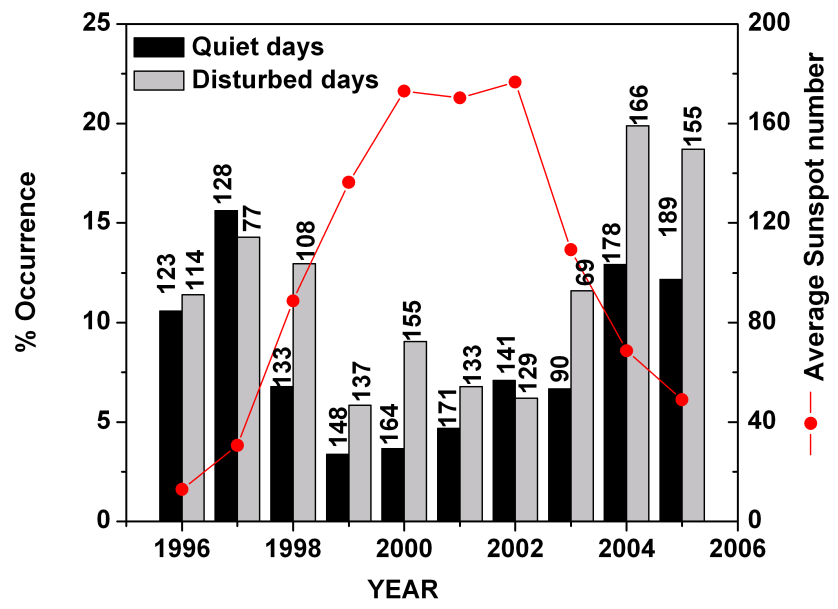

Fig. 2. Solar cycle variation of the F3 layer during quiet and disturbed times from 1996-2005. The total number of days on which data was available is written on top of each histogram.

\subsection{Statistics of occurrence of the F3 layer}

During the period from 1996-2005, the solar activity varied from minimum to maximum phase and then back to minimum. This helped in the investigation of the solar activity dependence of the F3 layer occurrence. Figure 2 shows the percentage occurrence of the $\mathrm{F} 3$ layer over Trivandrum for the quiet $\left(A_{\mathrm{p}}<8\right)$ and disturbed days $\left(A_{\mathrm{p}}>8\right)$ along with the average sunspot number during 1996-2005. The total number of quiet and disturbed days when data was available during each year is also shown in the figure. The percentage occurrence during the quiet/disturbed periods of each year is taken as the percentage number of quiet/disturbed days on which F3 layer was observed out of the total number of available quiet/disturbed days of that particular year. It is to be noted that the percentage occurrence of $\mathrm{F} 3$ layer is calculated on the basis of the appearance of the F3 layer in the ionograms, and this happens only when $N m \mathrm{~F} 3$ becomes greater than $N m \mathrm{~F} 2$. At later times, when $N m \mathrm{~F} 2$ becomes greater than $N m \mathrm{~F} 3$, the layer will not detected by the ground based ionosonde, though topside ledges could exist.

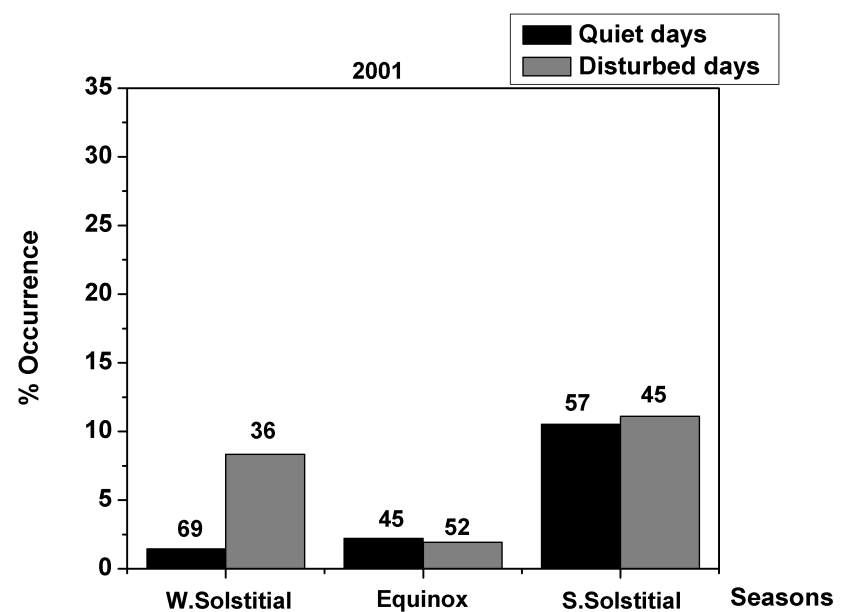

Fig. 3a. Seasonal variation in the F3 layer occurrence during quiet and disturbed days of the solar maximum year of 2001. The total number of days on which ionogram data was available during each season is shown in the top of the histogram.

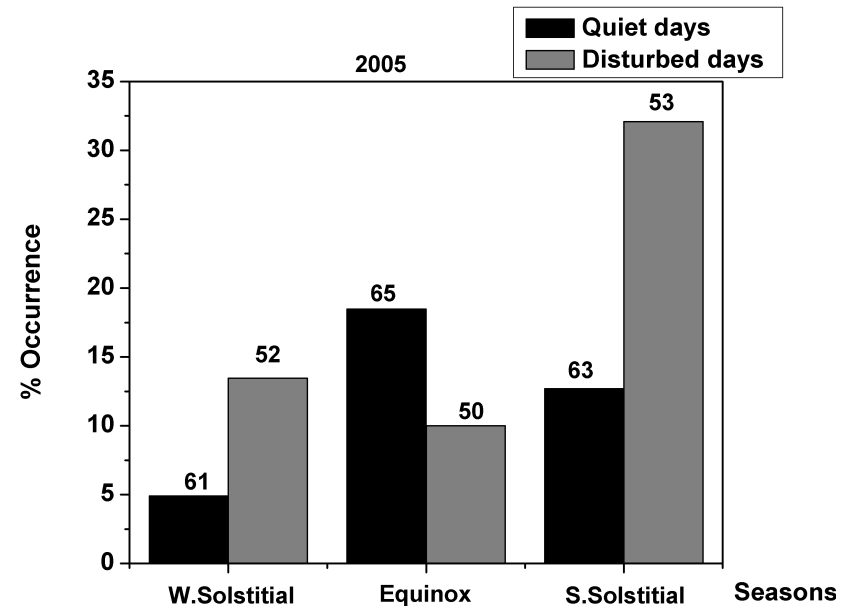

Fig. 3b. Same as for Fig. 3a, but for the solar minimum year of 2005.

It is very clear from Fig. 2 that the F3 layer occurrence over Trivandrum is very weak and rare, with the highest occurrence for the quiet days being only $16 \%$ in 1997. During the disturbed days, the highest occurrence is $20 \%$ in 2004 . Also, during the entire period of study (except in 1997 and 2002), the \% occurrence is higher during the disturbed days than during the quiet days, thus indicating the dependence of the F3 layer occurrence over Trivandrum on magnetic activity.

Another feature which is evident from this figure is the solar activity dependence of the F3 layer occurrence. For both the quiet as well as the disturbed days, the occurrence of the F3 layer is higher during the low solar activity period (19961997 and 2004-2005). With the increase in the solar activity from 1996 to 2000, the F3 layer occurrence for the quiet days 


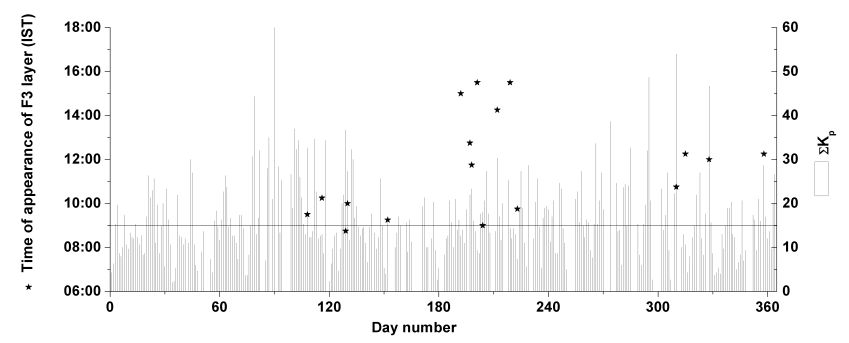

Fig. 4a. Variation in the time of appearance of the F3 along with the daily average $K_{p}\left(\Sigma K_{p}\right)$ during 2001. F3 layer was observed for 17 days.

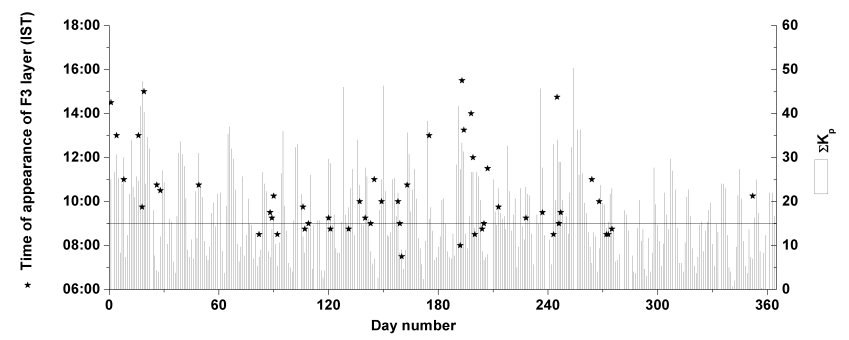

Fig. 4b. Same as for Fig. 4a, but during 2005. F3 layer was observed for 53 days.

decreased from $11 \%$ to $4 \%$, whereas for the disturbed days, the occurrence decreased from $11 \%$ to $9 \%$. The characteristics of the F3 layer occurrence during the solar maximum year of 2001 and the minimum year of 2005 are discussed subsequently.

It is clear from Fig. 2 that the occurrence of the F3 layer during the quiet and disturbed days of the solar maximum year of 2001 is 5\% and 7\%, respectively. For the quiet and disturbed days of the solar minimum year of 2005, the F3 layer occurrence is $13 \%$ and $19 \%$, respectively. The seasonal occurrence pattern of $\mathrm{F} 3$ during the quiet and disturbed days of 2001 and 2005 are shown in Fig. 3a and b, respectively. The seasons are defined as: Winter Solstitial (January, February, November and December), Equinox (March, April, September and October) and Summer Solstitial (May, June, July and August). The total number of days on which data was available during each season is also shown on top of the histogram.

From Fig. 3a, it is clear that for the quiet days of 2001, the occurrence is higher during the summer solstitial months with occurrence of $11 \%$ and lowest during the winter solstitial months with $2 \%$ occurrence. But for the disturbed days, the occurrence is higher both during the winter as well as the summer solstitial months respectively with $8 \%$ and $11 \%$ occurrence. During the solar minimum year of 2005 (Fig. 3b), for the quiet days, the highest occurrence is during the equinox with $19 \%$. The quiet days of the summer solstitial months have an F3 layer occurrence of 13\%. However, during the disturbed days of 2005 , the summer solstitial months have the highest occurrence with $32 \%$ and the lowest occurrence is during the equinox with $10 \%$. This illustrates that the occurrence of the F3 layer exhibits large seasonal variability both under magnetically quiet as well as disturbed days.

The day-to-day variation in the time of appearance of the F3 layer in the ionograms along with the daily average $K_{p}\left(\Sigma K_{p}\right)$ during 2001 and 2005 is shown in Fig. $4 \mathrm{a}$ and b, respectively. It is clear from these figures that the layer occurs both during magnetically quiet $\left(\Sigma K_{p}<15\right)$ as well as active conditions during both the years. The $\Sigma K_{p}<15$ is chosen as the threshold to represent magnetically quiet conditions because the mean of the $\Sigma K_{p}$ values for both the years is around 15. From Fig. $4 a$ and b, it is clear that the time of appearance of the F3 layer shows large day-to-day variability. The F3 layer occurs from as early as 08:00 IST to as late as 16:00 IST in both the years. For the quiet days of the solar maximum year of 2001 and the minimum year of 2005 , irrespective of the seasons, on an average, the layer occurs during the morning hours (09:00-11:00 IST). But, during the magnetically active days, the F3 layer can occur at any time from morning till evening (08:00-16:00 IST).

\section{Discussions}

Many of the features of the F3 layer observed above are in general agreement with the model calculations of Balan et al. (1998) that explain the formation of the F3 layer during quiet days as due to the combined effects of the vertical $\boldsymbol{E} \times \boldsymbol{B}$ drift and equatorward neutral winds. Our data shows that the F3 layer occurrence over the magnetic equatorial location of Trivandrum is very weak and rare compared to other equatorial locations, though model results (Balan et al., 1997) predict the F3 layer occurrence over Trivandrum as at other equatorial latitudes. The difference between the model results and observations could be mainly due to the variation in the actual $\boldsymbol{E} \times \boldsymbol{B}$ drift at Trivandrum and that (at Jicamarca) used in models. However, this result of the weak F3 layer occurrence over Trivandrum corroborates with that of Rama Rao et al. (2005). They have shown that in the Indian longitudes, the percentage occurrence of F3 layer over Waltair $\left(17.7^{\circ} \mathrm{N} ; 83.3^{\circ} \mathrm{E}\right.$; dip lat $\left.\sim 8.2^{\circ} \mathrm{N}\right)$ is almost $100 \%$ during the summer months (June, July and August) of the low solar activity period of 1997-1999. Their study indicated that Waltair could be the location where the resultant upward vertical drift due to $\boldsymbol{E} \times \boldsymbol{B}$ drift and neutral winds becomes exactly vertical, and hence is the most favorable location for the F3 layer occurrence.

Our data also clearly indicate the solar activity variations in the F3 layer occurrence. The occurrence of the layer is higher during the low solar activity periods, which is in agreement with the observational results obtained from other equatorial locations (Rama Rao et al., 2005; Batista et al., 2002). Balan et al. (1998) have modeled the $N_{\mathrm{e}}$ profiles 
for different solar activity conditions, which indicate that the ionosphere becomes broad and intense with the increasing solar activity, while the $\boldsymbol{E} \times \boldsymbol{B}$ drift and the winds remains more or less constant. Thus, during solar maximum periods, the upward force arising from the drift and winds becomes less efficient to lift the morning F2 peak to the topside altitude to form the F3 layer.

The seasonal variation in the F3 layer occurrence during both quiet as well as magnetically active conditions is another feature evident from the above observations. Rama Rao et al. (2005) and Batista et al. (2002) have shown that the F3 layer occurrence over Waltair and Fortaleza is more during the local summer months $(>75 \%)$ and minimal during the equinoctial months. Our data shows that over Trivandrum during the quiet days of the solar maximum year of 2001, the F3 layer occurrence is higher during the local summer months, corroborating the earlier results. But, for the quiet days of the solar minimum year of 2005, the occurrence is higher during the equinox. Zain et al. (2008) have reported that over the equatorial region of Malaysia during the solar minimum year of 2005, the F3 layer occurrence is more pronounced during the winter and equinoxes. Their study shows that there is an absence of the F3 layer occurrence during the summer months of May, June, July and August. For the disturbed days of both the solar maximum as well as the minimum year, the summer solstitial months are characterized by higher F3 layer occurrence.

The time of appearance of the F3 layer during the quiet days is in accordance with the model simulations by Balan et al. (2000), where they have shown that if the time cumulative vertical velocity provides an upward drift between 07:00 and 11:00 LT, then an F3 layer forms. The day-to-day variations in the F3 layer occurrence arise from the corresponding variations in the vertical plasma drift.

A new and interesting result from the study is the magnetic activity dependence of the F3 layer occurrence. The earlier studies on the F3 layer occurrence did not distinguish between the magnetically quiet and active conditions (Lynn et al., 2000; Batista et al. 2002; Rama Rao et al., 2005; Zain et al., 2008). It is observed that over Trivandrum within a particular year, the occurrence of the F3 layer is higher during the disturbed days than during the quiet days. This indicates that the electrodynamical and neutral dynamical modulations caused by geomagnetic disturbances provide favorable conditions for the F3 layer development over Trivandrum.

\section{Conclusions}

The general features of the F3 layer over the magnetic equatorial location of Trivandrum during a solar cycle from 19962005, with emphasis on a solar maximum year of 2001 and a minimum year of 2005 are discussed. The study brings out that the F3 layer occurrence over Trivandrum is weak and rare compared to the other equatorial locations. The occur- rence is higher during periods of low solar activity than under periods of high solar activity. The most important outcome of this present study is that the occurrence probability of the F3 layer over Trivandrum during a particular year is higher during the disturbed days compared to the quiet days.

Acknowledgements. This work was supported by Department of Space, Government of India. One of the authors, V. Sreeja, gratefully acknowledges the financial assistance provided by the Indian Space Research Organization through Research Fellowship.

Topical Editor K. Kauristie thanks A. F. Zain and another anonymous referee for their help in evaluating this paper.

\section{References}

Bailey, G. J. and Balan, N.: A low-latitude ionosphereplasmasphere model, in STEP Handbook, edited by: Schunk, R. W., p. 173, Utah State Univ., 1996.

Bailey, G. J., Balan, N., and Su, Y. Z.: The Sheffield University plasmasphere-ionosphere model-A review, J. Atmos. Sol. Terr. Phys., 59, 1541-1552, 1997.

Balan, N. and Bailey, G. J.: Equatorial plasma fountain and its effects: Possibility of an additional layer, J. Geophys. Res., 100, 21421-21432, 1995.

Balan, N., Bailey, G. J., Abdu, M. A., Oyama, K. I., Richards, P. G., Macdougall, J., and Batista, I. S.: Equatorial plasma fountain and its effects over three locations: Evidence for an additional layer, the F3 layer, J. Geophys. Res., 102, 2047-2056, 1997.

Balan, N., Batista, I. S., Abdu, M. A., Macdougall, J., and Bailey, G. J.: Physical mechanism and statistics of occurrence of an additional layer in the equatorial ionosphere, J. Geophys. Res., 103, 29169-29181, 1998.

Balan, N., Batista, I. S., Abdu, M. A., Bailey, G. J., Watanabe, S., Macdougall, J., and Sobral, J. H. A.: Variability of an additional layer in the equatorial ionosphere over Fortaleza, J. Geophys. Res., 105, 10603-10613, 2000.

Balan, N., Thampi, S. V., Lynn, K., Otsuka, Y., Alleyne, H., Watanabe, S., Abdu, M. A., and Fejer, B. G.: F3 layer during penetration electric field, J. Geophys. Res., 113, A00A07, doi:10.1029/2008JA013206, 2008.

Batista, I. S., Abdu, M. A., McDougall, J., and Souza, J. R.: Long term trends in the frequency of occurrence of the F3 layer over Fortaleza, J. Atmos. Sol. Terr. Phys., 64, 1409-1412, 2002.

Fejer, B. G., de Paula, E. R., Gonzales, S. A., and Woodman, R. F.: Average vertical and zonal $\mathrm{F}$ region plasma drifts over Jicamarca, J. Geophys. Res., 96, 13901-13906, 1991.

Hedin, A. E., Biondi, M. A., Burnside, R. G., et al.: Revised global model of thermosphere winds using satellite and ground-based observations, J. Geophys. Res., 96, 7657-7688, 1991.

Heisler, L. H.: The anomalous ionospheric stratification F1.5, J. Atmos. Sol. Terr. Phys., 24, 483-489, 1962.

Jenkins, B., Bailey, G. J., Abdu, M. A., Batista, I. S., and Balan, N.: Observations and model calculations of an additional layer in the topside ionosphere above Fortaleza, Brazil, Ann. Geophys., 15, 753-759, doi:10.1007/s00585-997-0753-3, 1997.

King, J. W., Smith, P. A., Eccles, D., Fooks, G. F., and Helm, H.: Preliminary investigation of the structure of the upper atmosphere as observed by the topside sounder satellite, Alouette, Proc. R. Soc. London, Ser. A, 281, 464-487, 1964. 
Lockwood, G. E. K. and Nelms, G. L.: Topside sounder observations of the equatorial anomaly in the $75 \mathrm{~W}$ longitude zone, J. Atmos. Terr. Phys., 26, 569-580, 1964.

Lynn, K. J. W., Harris, T. J., and Sjarifudin, M.: Stratification of the F2 layer observed over Southeast Asia, J. Geophys. Res., 105, 27147-27156, 2000.

Paznukhov, V. V., Reinisch, B. W., Song, P., Huang, X., Bullett, T. W., and Veliz, O.: Formation of an F3 layer in the equatorial ionosphere: A result from strong IMF changes, J. Atmos. Sol. Terr. Phys., 69, 1292, doi:10.1016/j.jastp.2006.08.019, 2007.

Raghavarao, R. and Sivaraman, M. R.: Ionization ledges in the equatorial ionosphere, Nature, 249, 331-332, 1974.

Rama Rao, P. V. S., Niranjan, K., Prasad, D. S. V. V. D., Brahmanandam, P. S., and Gopikrishna, S.: Features of additional stratification in ionospheric F2 layer observed for half a solar cycle over Indian low latitudes, J. Geophys. Res., 110, A04307, doi:10.1029/2004JA010646, 2005.

Ratcliffe, J. A.: Some regularities in the F2 Region of the Ionosphere, J. Geophys. Res., 56, 487-507, 1951.

Sayers, J., Rothwell, P., and Wager, J. H.: Field aligned strata in the ionization above the ionospheric F2 layer, Nature, 198, 230-233, 1963.

Sen, H. Y.: Stratification of the $F_{2}$ layer of the ionosphere over Singapore, J. Geophys. Res., 54, 363-366, 1949.

Skinner, N. J., Brown, R. A., and Wright, R. W.: Multiple stratification of the F-layer at Ibadan, J. Atmos. Sol. Terr. Phys., 5, 92-100, 1954.
Sreeja, V., Balan, N., Ravindran, S., Pant, T. K., Sridharan, R., and Bailey, G. J.: Additional stratifications in the equatorial $\mathrm{F}$ region at dawn and dusk during geomagnetic storms: Role of electrodynamics, J. Geophys. Res., 114, A08309, doi:10.1029/2009JA014373, 2009.

Thampi, S. V., Ravindran, S., Devasia, C. V., Pant, T. K., Sreelatha, P., and Sridharan, R.: First observation of topside ionization ledges using radio beacon measurements from low Earth orbiting satellites, Geophys. Res. Lett., 32, L11104, doi:10.1029/2005GL022883, 2005.

Uemoto, J., Ono, T., Kumamoto, A., and Iizima, M.: Ionization ledge structures observed in the equatorial anomaly region by using PPS system on-board the Ohzora (EXOS-C) satellite, Earth Planets Space, 56, E21-E24, 2004.

Uemoto, J., Ono, T., Kumamoto, A., and Iizima, M.: Statistical analysis of the ionization ledge in the equatorial ionosphere observed from topside sounder satellites, J. Atmos. Sol. Terr. Phys., 68, 1340-1351, 2006.

Uemoto, J., Ono, T., Maruyama, T., Saito, S., Iizima, M., and Kumamoto, A.: Magnetic conjugate observation of the F3 layer using the SEALION ionosonde network, Geophys. Res. Lett., 34, L02110, doi:10.1029/2006GL028783, 2007.

Zain, A. F. M., Abdullah, S., Homam, M. J., Seman, F. C., Abdullah, M., and Ho, Y. H.: Observations of the F3 layer at equatorial region during 2005, J. Atmos. Sol. Terr. Phys., 70, 918-925, 2008. 